\title{
A exaltação polissêmica do conceito de território: uma nova abordagem no efêmero período das políticas brasileiras de desenvolvimento territorial
}

\author{
The polysemic exaltation of the concept of territory: a new approach in the \\ ephemeral period of Brazilian territorial development policies
}

\author{
William Melo' \\ Camila da Silva Vieira ${ }^{2}$
}

\section{Resumo}

Neste paper, os autores visam problematizar alguns pressupostos conceituais erigidos com as últimas políticas de desenvolvimento territorial executadas pelo extinto Ministério do Desenvolvimento Agrário (MDA) nos governos de Fernando Henrique Cardoso; Luís Inácio Lula da Silva e Dilma Rousseff. Sendo assim, baseando-se na compreensão do território como uma esfera multidimensional, na importância da participação e do combate a pobreza em prol do desenvolvimento, este paper abordará: 1) o território na perspectiva do conceito de multiterritorialidade (HAESBAERT, 2004); 2) os demais modelos de políticas territoriais (modelo europeu e latino americano) que se utilizam ou se utilizaram de pressupostos conceituais em prol do desenvolvimento territorial; 3) a importância das políticas sociais como acréscimos estratégicos para as ações que fortalecem o desenvolvimento agrário brasileiro e;4) ressaltar a importância do Programa Território da Cidadania (PTC) como um importante avanço nas discussões e propostas para a questão agrária brasileira, demonstrando como o extinto programa colocava-se como uma ação favorável ao desenvolvimento territorial e de combate à extrema pobreza. Quanto ao método utilizado para o alcance das considerações realizadas, foi empregada a análise de documentos acrescida de revisão bibliográfica, o que permitiu o levantamento das fragilidades e potencialidades dos respectivos programas de desenvolvimento territorial brasileiro, entre os anos de 1994 a 2014.

Palavras-Chave: Território; Territorialidade; Política de Desenvolvimento Territorial; Políticas Sociais.

\begin{abstract}
In this paper, the authors aim to problematize some conceptual assumptions erected with the last policies of territorial development executed by the extinct Ministry of Agrarian Development (MDA) in the governments of Fernando Henrique Cardoso; Luís Inácio Lula da Silva and Dilma Rousseff, from 1994 to 2014. Based on the understanding of the territory as a multidimensional sphere, on the importance of participation and the fight against poverty for development, this paper will address: 1) the territory from the perspective of the concept of multiterritoriality (HAESBEART, 2004); 2) the other models of territorial policies (European and Latin American model) using or using conceptual assumptions in favor of territorial development; 3) the importance of social policies as strategic

\footnotetext{
1 Professor Visitante na UENF; PhD. em Ciência Política (UNICAMP) e Consultor da PORTVS Consultoria e Treinamento. E-mail: william_santos_melo@yahoo.com.br. Cidade: Rio de Janeiro.

2 Professora do CEDERJ/UERJ; Doutoranda em Geografia (UFF) e Consultora da PORTVS Consultoria e Treinamento. E-mail: camilavieira.ufrj@gmail.com. Cidade: Rio de Janeiro.
} 
additions to the actions that strengthen Brazilian agrarian development; 4) to highlight the importance of the Territory of Citizenship (PTC) program as an important advance in the discussions and proposals for the Brazilian issue, demonstrating how the extinction of the programs was an inappropriate initiative for the territorial territory and the fight against extreme poverty.

Keywords: Territory; Territoriality; Territorial Development Policy; Social Policies.

\section{Introdução}

O conceito de território sempre foi bastante estudado na ciência geográfica, tendo passado por uma evolução epistemológica até os dias atuais. A evolução conceitual da expressão territorial possibilitou uma concepção contemporânea de maximização do seu aproveitamento também pela perspectiva material (prática e objetiva), favorecendo que os grupos sociais passassem a exaltar a importância de sua ocupação, seu uso e a necessidade de controle pelas comunidades envolvidas. Isso implicou uma consideração do conceito ganhando significados de múltiplos poderes, heterogêneas identidades e infinitas funções, no intuito de traduzir as inumeráveis interpretações dadas ao território. A reflexão aqui realizada encontra-se, portanto, na direção de compreender o território como uma esfera dotada de incontáveis significados, ressaltando, por sua vez, a priorização da relação entre cultura e identidade territorial, possibilitando assim, avanços em relação às politicas territoriais até então estabelecidas no país.

Assim, a concepção aqui utilizada como fundamento das politicas públicas de desenvolvimento territorial no Brasil e no mundo, é aqui considerada como um avanço quando se trata de pensar o espaço ocupado e controlado pela sociedade. Esse movimento de utilização, especialmente em políticas públicas voltadas ao meio rural, teve início na Europa e foi proficuamente seguido pelos países latino-americanos. Neste sentido, o conceito de território passou a ser interpretado de forma polissêmica, destacando-se o seu caráter multiterritorial. A nova compreensão sobre o conceito de território passou também a ser promovido pela incorporação nas politicas de desenvolvimento territorial, renovando antigas concepções e 
levando a avanços (ou tentativas) para ações transformadoras em direção as expectativas e anseios das comunidades.

No Brasil, a concepção de território como múltipla em significados passou a ser mais explorada nos programas e politicas do extinto Ministério do Desenvolvimento Agrário (MDA), nos governos de Luís Inácio Lula da Silva, apresentando, até certo protagonismo nas ações em direção ao desenvolvimento territorial do país. Sua adoção inicia-se no Programa Nacional de Agricultura Familiar(Pronaf), elaborado com a finalidade de ofertar créditos subsidiados para a produção agropecuária e transversalmente diminuir as desigualdades sociais em áreas rurais do país, mas ganha contornos mais nítidos com a adoção do Programa de Desenvolvimento Sustentável dos Territórios Rurais (Pronat) e do Programa Territórios da Cidadania (PTC).

Sendo assim, este paper se utilizará da premissa e interpretação de que os programas executados a partir de meados da década de 1990,ajudaram na ressignificação da abordagem do território em direção a uma perspectiva multidimensional, levando em consideração as várias expressões de poder expressas pela sociedade, que se realizam nas esferas: econômica, sociocultural, político-institucional e ambiental. Compreendemos que é a partir do Pronaf, Pronat e PTC que é possivel realizar as reflexões, sobre:1) a utilização do conceito de território na perspectiva multidimensional; 2) as influências externas de demais políticas públicas territoriais como influenciadores das ações públicas nacionais; 3) a importância da sinergia entre as politicas sociais e as políticas territoriais numa tentativa de aplicabilidade em prol de posturas e ações em favor do desenvolvimento e da minimização das desigualdades territoriais brasileiras.

\section{O território e a multiterritorialidade: uma ressignificação necessária}

Nos estudos da ciência geográfica, o conceito de território foi - e continua sendo - amplamente estudado, especialmente no que concerne a sua definição e seus usos, evitando assim, interpretações equivocadas ou conflitos com outros conceitos geográficos que envolvam o espaço geográfico. 
Segundo Souza (2007), o território é fundamentalmente delimitado por e a partir de relações de poder, o que também é confirmado por Haesbaert (2007), ao afirmar que em qualquer que seja a abordagem a respeito do conceito de território, haverá poder envolvido, seja no sentido de dominação simbólica ou de apropriação. Nesse contexto, ressalta-se a experiência de Sack (2011) sobre o tema de controle do território, onde, segundo o autor, a delimitação de territórios consiste no resultado de estratégias construídas para afetar, influenciar e controlar pessoas, fenômenos e relações.

Para além da definição do conceito de território, alguns autores, a exemplo de Corrêa (1994), o consideram a partir de algumas dimensões, como política, afetiva e social. Assim, o território ganha outros significados, se expande em sua definição e proporciona o entendimento do conceito de territorialidade, especialmente a partir da abordagem afetiva do território. Neste sentido, segundo Raffestin (1993), pode-se dizer que a territorialidade é estabelecida a partir da relação entre seres humanos mediatizada no território, ou seja, a partir de relacionamentos sociais construídos territorialmente.

O entendimento do conceito de territorialidade torna-se importante, na medida em que permite a compreensão do relacionamento que pode existir entre o homem e o espaço por ele ocupado. Esse espaço geográfico, apropriado pelo homem (território) admite processos sociais e afetivos de pertencimento a essa área geográfica (territorialidade) e como consequência, pode desencadear processos de desterritorialização e reterritorialização.

Por sua vez, esses processos de desterritorialização e reterritorialização ocorrem especificamente quando os indivíduos são retirados de seus espaços habituais de moradia e realocados em outros espaços. No entanto, esses processos sempre ocorrem, pois sempre existirá uma condição de afetividade com o espaço geográfico ocupado, entendido então como território e refletindo a territorialidade envolvida. Assim, no momento em que o indivíduo é retirado desse território ocorre a dinâmica da desterritorialização, e quando começa a estabelecer um relacionamento 
afetivo com o novo território para o qual foi realocado, ocorre à dinâmica da reterritorialização.

É válido destacar que esses dois processos podem ocorrer de maneira diferenciada dentro da sociedade, gerando consequências também distintas. No caso de o indivíduo modificar seu local de habitação de maneira voluntária, provavelmente terá melhores condições de se adaptar ao novo local de moradia e, consequentemente, de construir novamente seus laços afetivos com o espaço ocupado. Por outro lado, existem processos que ocorrem "de forma verticalizada", ou seja, indivíduos retirados à força de seus locais de moradia e realocados em outros; é o caso de remoções e reassentamentos realizados pelos governos, nos quais estes sujeitos terão mais dificuldades de edificar sentimentos em relação ao novo espaço. Assim, se constituem processos de desterritoralização e reterritorialização forçados, o que sem dúvidas os tornam mais traumáticos e dificultam a dinâmica de adaptação territorial.

Ainda sobre esse tema, segundo Haesbaert (2007), os dois processos em discussão não podem ocorrer de maneira isolada, ou seja, a desterritorialização é um processo indissociável da reterritorialização, sendo este dialético. E é por esse motivo que o autor trata a desterritorialização como um "mito", não pelo fato de não existir, mas por existir somente de forma associada à reterritorialização. Para defender essa ideia, Haesbaert (2007) afirma que o homem é um “animal territorial” e, portanto, todos esses processos são inerentes às suas ações, formando um movimento complexo de territorialização, que incluiria a vivência de diversos territórios ao mesmo tempo, ou, finalmente, da multiterritorialidade.

Desse modo, a multiterritorialidade surge como uma alternativa conceitual ao processo chamado até então de desterritorialização (HAESBAERT, 2007). Isso porque, o autor acredita que a dinâmica que ocorre consiste mais fortemente na intensificação e na complexificação de um processo que é muito mais múltiplo ou referente a inúmeros territórios; na verdade, segundo o autor, quando da desterritorialização não ocorre essa "perda" ou destruição de um território ou do processo de territorialização, na 
medida em que o território não é constituído somente de uma dimensão; pelo contrário, o território é sempre múltiplo, "diverso e complexo" (HAESBAERT, 2007). Portanto, todos esses processos não devem ser abordados de maneira setorizada, mas sim conjuntamente e na multiplicidade de suas manifestações.

Dessa forma, a multiterritorialidade contemporânea, de acordo com Haesbaert (2007), inclui não somente a incorporação de uma visão quantitativa, na ideia de agrupar uma maior quantidade de territórios, como também qualitativa, já que existe a possibilidade de levar em consideração a vivência - pelos atores e ações realizadas - inerente a esses territórios ou suas manifestações de territorialidade. Ou seja, essa concepção múltipla de território leva em consideração também a existência não só de vários processos coexistindo, como também de variados atores e poderes convivendo no mesmo espaço geográfico.

Assim, o caráter multidimensional do território que deu o tônus da política de desenvolvimento territorial outrora executado (Pronaf, Pronat e em especial no PTC), passou a considerar as várias expressões de poder que a sociedade pode expressar: econômica, sociocultural, político-institucional e ambiental (ver quadro 1). Neste sentido, a ampliação desse conceito levou a um entendimento de que o território é polissêmico e passa a apresentar significado a partir da ocupação e relação que a sociedade estabelece com sua localidade. 


\section{Quadro 1- Características das políticas brasileiras de desenvolvimento territorial}

\begin{tabular}{|c|c|c|c|c|}
\hline PROGRAMAS & OBJETIVOS & AÇÕES & PUBLICO ALVO & PERÍODO \\
\hline $\begin{array}{l}\text { Programa } \\
\text { Nacional de } \\
\text { Agricultura } \\
\text { Familiar } \\
\text { (Pronaf) }\end{array}$ & $\begin{array}{l}\text { Financiar e apoiar } \\
\text { projetos agrários, } \\
\text { individuais ou } \\
\text { coletivos, que } \\
\text { possibilitem geração } \\
\text { de renda aos } \\
\text { agricultores } \\
\text { familiares e } \\
\text { trabalhadores rurais } \\
\text { assentados. }\end{array}$ & $\begin{array}{l}\text { 1) Atender as demandas e } \\
\text { necessidades de pequenos } \\
\text { produtores rurais; } 2 \text { ) } \\
\text { Possibilitar a elevação da } \\
\text { capacidade produtiva dos } \\
\text { municipios atendidos; 3) } \\
\text { Gerar emprego e renda para } \\
\text { agricultores familiares e } \\
\text { assentados; 4) Contribuir no } \\
\text { combate às desigualdades } \\
\text { sociais existentes na esfera } \\
\text { rural brasileira; 5) Estimular e } \\
\text { utilizar de forma eficiente o } \\
\text { trabalho da agricultura } \\
\text { familiar }\end{array}$ & $\begin{array}{l}\text { Agricultores e } \\
\text { produtores rurais } \\
\text { pertencentes a } \\
\text { unidades } \\
\text { familiares de } \\
\text { produção rural }\end{array}$ & $\begin{array}{l}\text { Inicio: } 1996 \\
\text { Término: } \\
\text { Em vigência }\end{array}$ \\
\hline $\begin{array}{l}\text { Programa de } \\
\text { Desenvolviment } \\
\text { o Sustentável } \\
\text { dos Territórios } \\
\text { Rurais (Pronat) }\end{array}$ & $\begin{array}{c}\text { Descentralização } \\
\text { das políticas } \\
\text { públicas de } \\
\text { desenvolvimento } \\
\text { territorial, além da } \\
\text { valorização da } \\
\text { participação dos } \\
\text { atores locais, } \\
\text { incluindo ONGs e } \\
\text { beneficiários, } \\
\text { empoderando as } \\
\text { instituições locais } \\
\text { como propulsoras do } \\
\text { desenvolvimento. }\end{array}$ & $\begin{array}{l}\text { 1) Gestão social; 2) Redes } \\
\text { sociais de cooperação; 3) } \\
\text { Dinamização economica dos } \\
\text { territórios; 4) Articulação de } \\
\text { politicas setoriais. }\end{array}$ & $\begin{array}{l}\text { Agricultores, } \\
\text { produtores rurais e } \\
\text { demais atores } \\
\text { pertencentes à } \\
\text { esfera rural } \\
\text { brasileira. }\end{array}$ & $\begin{array}{l}\text { Inicio: } 2003 \\
\text { Término: } \\
2014\end{array}$ \\
\hline $\begin{array}{c}\text { Programa } \\
\text { Territórios da } \\
\text { Cidadania (PTC) }\end{array}$ & $\begin{array}{c}\text { Apresentar novas } \\
\text { ações sociais via } \\
\text { articulação das } \\
\text { numerosas politicas } \\
\text { já existentes, } \\
\text { objetivando criar } \\
\text { efeitos territoriais } \\
\text { sinérgicos através de } \\
\text { alcance da } \\
\text { intersetorialidade, } \\
\text { possibilitando ainda } \\
\text { a identificação de } \\
\text { regiões carentes, } \\
\text { nas quais } \\
\text { programas e } \\
\text { projetos sociais } \\
\text { deveriam ter } \\
\text { prioridade máxima. }\end{array}$ & $\begin{array}{l}\text { 1) Apoio a Atividades } \\
\text { Produtivas; 2) Cidadania e } \\
\text { Direito e; 3) Infraestrutura. }\end{array}$ & $\begin{array}{c}\text { Territórios } \\
\text { fragilizados; } \\
\text { agricultores } \\
\text { familiares; } \\
\text { quilombolas; } \\
\text { pescadores e } \\
\text { população } \\
\text { indigena. }\end{array}$ & $\begin{array}{l}\text { Inicio: } 2003 \\
\text { Término: } \\
2014\end{array}$ \\
\hline
\end{tabular}


Fonte: Elaboração própria.

A abordagem utilizada pelas políticas de desenvolvimento territorial iniciadas em meados dos anos de 1990 demonstra uma real importância com a nova conceitualização do território acrescida de uma necessidade de valorização dos demais atores agrários, onde se exaltará: 1) a denominação de agricultores familiares como forma de abrandar os conflitos existentes; 2) inserir todo um conjunto de atores locais outrora relegados pelas ações da União e; 3) realizar uma ação política em sinergia com as melhoras práticas desenvolvidas na Europa e nos países Latino-americanos, demonstrando como a agenda externa e as novas abordagens sobre a matéria será significativamente absorvida em direção a novos interpretações/rumos pelos atores políticos e demais especialistas prioritariamente em direção ao desenvolvimento do campesinato brasileiro.

\section{As influências externas e a possibilidade de um "novo" estágio para as políticas territoriais brasileiras}

De forma inovadora, a mudança conceitual do território passa também a renovar a concepção sobre a compreensão do que pode se definir como desenvolvimento rural. Como analisa Abramovay (2005) a utilização da noção de território como fundamento das políticas públicas de desenvolvimento no meio rural iniciou-se na Europa, posteriormente foi sendo incorporado por países latino-americanos, apresentando como virtudes: 1) o abandono de um horizonte estritamente setorial, refinando assim os instrumentos estatísticos que delimitam a ruralidade (organização de seus ecossistemas, densidade demográfica relativamente baixa, sociabilidade de interconhecimento e dependência com relação às cidades) e a definição de territórios antes pela maneira como se produz, em seu interior, a interação social, que pelos seus limites físicos; 2) a distinção entre crescimento econômico e processo de desenvolvimento e; 3) a ênfase na forma como uma sociedade utiliza os recursos de que dispõe em sua 
organização produtiva e, portanto, na relação entre sistemas sociais e ecológicos.

Já segundo Beduschi Filho e Abramovay, a Organização para Cooperação e Desenvolvimento Econômico (OCDE) fortaleceu ainda mais a nova perspectiva territorial, já que passou a editar uma publicação anual periódica a respeito da temática, entendendo que "[...] cada território disp[unha] de um capital específico, o capital territorial" (OCDE, 2001, p.15 apud BEDUSCHI FILHO; ABRAMOVAY, 2004, p. 38, grifos dos autores). Nessa perspectiva, o território passou assim, a ter uma identidade própria, onde seu desenvolvimento passou a integrar não apenas fatores naturais, mas, sobretudo, fatores sociais, politicos e econômicos. O desenvolvimento territorial passa então a ser definitivamente compreendido como um processo de empowerment, onde deve ser construído em atendimento às demandas mais significativas do território, de acordo com a aprovação social.

Imbuídas deste novo discurso para o desenvolvimento, os governos de vários países - inclusive o governo brasileiro - viram-se fortalecidos com os pressupostos teóricos conceituais do Banco Mundial, da Organização das Nações Unidas para Agricultura e Alimentação (FAO), da Comissão Econômica para América Latina e Caribe (CEPAL) e da Organização para a Cooperação e o Desenvolvimento Econômico (OCDE), e passaram então a difundir e apoiar a abordagem territorial a partir de metas e objetivos na direção de uma nova abordagem do desenvolvimento territorial.

[Foi] enorme a influência destes organismos sobre a definição das políticas, sobretudo dos países da periferia e da semi-periferia do capitalismo mundial. O que se deve tanto ao papel de financiador de muitos desses organismos, como, talvez principalmente, pelo fato de funcionarem como uma espécie de pivô, através do qual gira uma articulação muito peculiar de interesses e competências envolvendo o campo acadêmico, político, econômico [...]. (FAVARETO, 2006, p. 3, grifos dos autores).

$\mathrm{Na}$ concepção estabelecida a partir da nova abordagem do território, surge como uma das primeiras iniciativas de politica de desenvolvimento territorial a Liaison Entre Actions de Développement de l'Économie 
Rurale(LEADER). Surgida no inicio da década de 1990 em meio as reformulações da Política Agrícola Comum (PAC) da Europa, teve por desenho institucional destinado as áreas rurais uma concepção de arquitetura alicerçada em ações de bottom-up ${ }^{3}$, tendo como princípio sua multissetorialidade.

A abrangência do programa na primeira fase da LEADER (19911994), segundo Hespanhol (2008), contou com aportes financeiros de 417 milhões de Euros, financiando 217 projetos. Nesta fase, os projetos desenvolvidos pela LEADER tinham como foco principal privilegiar as "áreas desfavorecidas” de países como Portugal, Espanha e Grécia. Por “zonas desfavorecidas subentendia-se a concentração de agricultores que não ascenderam ao padrão tecnológico hegemônico na agricultura atual" (ORTEGA et al, 2008, p. 73). Posteriormente, em sua segunda fase (19951999), a LEADER II, segundo Hespanhol (2008), contou com 1,75 bilhões de euros e apoiou 906 projetos e, na sua última fase, o LEADER + (2000-2006) contou com 2,02 bilhões de euros e teve como proposta estender os benefícios a todos os países membros (europeus) promovendo a dinâmica territorial numa perspectiva de superar a visão setorial entre o rural e o urbano.

A proposta metodológica da LEADER procurou estimular a competitividade territorial, envolvendo os diversos atores sociais, o governo, as instituições e as empresas, de modo que o esforço coletivo construísse uma articulação coesa na elaboração e na aplicação dos projetos de desenvolvimento, que deveriam ser selecionados por seu mérito. O elemento mediador de tal processo ocorria pelos Grupos de Ação Local (GAL), segundo Ortega et al(2008, p. 99), muito semelhante ao que ocorria nas politicas de desenvolvimento territorial brasileiras, com a presença de arquiteturas

${ }^{3} \mathrm{O}$ termo bottom-up traz o significado de uma abordagem realizada de baixo para cima. Ela consiste em um processo de análise e comportamento de informações que utiliza a compreensão de subdivisões dos assuntos para uma percepção mais completa e com uma nova interpretação das partes que formam o todo, ou seja, analisa e descreve os elementos mais básicos para formar um resultado maior. No que se refere a politicas públicas, uma ação bottom-up descreve uma ação política que leva em consideração as demandas e opiniões do público-alvo, onde o caráter participativo e dialógico se destaca na relação entre o Estado, a sociedade civil e a iniciativa privada. 
participativas. Neste sentido, a LEADER foi toda ancorada a partir do conceito de empowerment dos atores sociais em beneficio das multiterritorialidades, o que o levou a ser um modelo inspirador para as politicas territoriais posteriores executadas em países periféricos e em importantes economias, que por atraso, ainda apresentavam fragilidades no que se refere ao desenvolvimento campesino (como é o caso do Brasil).

Favareto (2010) considera ainda, que esta nova abordagem territorial - adotada na LEADER - é explicada, por um lado, pelo reconhecimento de novas dinâmicas espaciais, e de outro, pelo momento histórico marcado por certo realinhamento dos instrumentos tradicionais de promoção do desenvolvimento. Por exemplo, a descentralização das políticas públicas e da atividade industrial, associada à redução e ao redirecionamento da intervenção estatal, contribuiu para que, particularmente depois de meados da década de 1980, se instituísse um padrão em que, em lugar dos investimentos diretos e de corte setorial, caberia ao Estado criar condições e um ambiente a partir do qual os próprios atores pudessem fazer alocação dos recursos humanos e materiais.

Posteriormente, por volta da segunda metade da década de 1990, os países membros do Mercado Comum do Sul (MERCOSUL) por meio de suas entidades públicas começaram a realizar atividades de intercâmbio de políticas públicas e de promoção do desenvolvimento rural, ao passo que também discutiam um novo formato de gestão que superasse as limitações dos resultados até então conquistados. Neste sentido, temas como descentralização, participação social, nova institucionalidade, multifuncionalidade da agricultura e do trabalho rural, dentre outros, passaram a ser incluídos nos eixos norteadores de politicas públicas para o desenvolvimento rural nestes países (SEPULVEDA; GUIMARÃES, 2008).

As iniciativas de desenvolvimento territorial no espaço rural passam a ocorrer em diversos níveis de políticas públicas. O grande impulso rumo a uma nova direção ocorre com a criação da Secretaria de Desenvolvimento Territorial (SDT) como componente institucional do Ministério do Desenvolvimento Agrário (MDA) e de sua incorporação ao Programa 
Plurianual do Governo, tendo por protagonismo o Pronat, que adota o enfoque territorial e passa a exaltar novos e participativos métodos e instrumentos de gestão. Esta nova abordagem, que depois se demonstrou momentânea (e definitivamente abandonada em meados dos anos de 2014), foi referência para a condução de politicas públicas de desenvolvimento rural no país, construindo, desta forma, uma nova concepção conceitual para enfrentar os problemas estruturais vivenciados pela sociedade rural nos territórios brasileiros (SEPULVEDA; GUIMARÃES, 2008).

Os programas que anteriormente promoviam o desenvolvimento rural com politicas e investimentos sociais a nivel territorial; fortalecendo a agricultura familiar e o combate à pobreza, são violentamente interrompidos no segundo mandato da então presidenta Dilma Rousseff, que passa a privilegiar uma política econômica de corte a investimentos públicos. As iniciativas em prol do desenvolvimento territorial brasileiro que anteriormente apoiavam os atores sociais com trajetórias e interesses nitidamente diversos, assemelhando-se a transformação das principais vantagens comparativas em vantagens competitivas destes distintos atores são substancialmente esvaziadas. Os desenhos dos programas, que sofriam nítida influência da Europa - principalmente do programa LEADER -, em sua conformação institucional e nos avanços obtidos a partir da inspiração europeia de uma nova abordagem para o conceito de território passam a partir do ano de 2014 a não mais fazerem parte da agenda governamental brasileira.

Anteriormente ao abandono da politica, foi possivel perceber que as ações de desenvolvimento territorial no Brasil, passaram a ser municipalizadas, empregadas para designar a apropriação da política pública por grupos ligados aos interesses dos governantes locais, abrindo assim precedentes para o oportunismo de particulares que passaram a centralizar a decisões nestes espaços de diálogo, elaborando projetos para seu beneficiamento pessoal. Rover e Henriques (2006) chegam a afirmar que muitas das ações de desenvolvimento local tenderiam a não se efetivar ao público mais necessitado, sendo resultado: 
[...] do fato de elas estarem diretamente ligadas às autarquias locais, reproduzindo, por vezes, uma lógica de clientela, tendendo a projetos ligados aos grupos politicos e econômicos dominantes no local. Estes grupos exerciam um tipo de poder que os colocavam mais próximos das redes de decisão das políticas locais do que outros cidadãos (ROVER; HENRIQUES, 2006, p. 132).

Estes desvios, que já tinham sido evidenciados na política de desenvolvimento territorial da Europa, também foram sentidos na fase de execução da política brasileira ${ }^{4}$, demonstrando que a autonomia e o desenvolvimento equânime para os atores sociais do meio rural, além de apresentarem distorções e erros em suas concepções, apresentavam-se como incômodos às expectativas e anseios por parte do latifúndio, tornando-se logo secundários na agenda-setting da elite campesina (o agronegócio).

\section{Do nada para lugar algum: o contemporâneo desenvolvimento territorial brasileiro}

O desenvolvimento territorial atrelado a políticas sociais no Brasil ganhou força no final da gestão do ex-presidente Fernando Henrique Cardoso, quando se retoma a preocupação referente a políticas de desenvolvimento nos setores agrícolas proveniente da necessidade de mediar à crise ocorrida no Pará entre latifundiários e trabalhadores sem terra, que resultou no Massacre de Eldorado dos Carajás. A partir deste momento emerge a discussão sobre um novo patamar de desenvolvimento que, associada à noção de sustentabilidade, se definia como: imprecisa, vago e de dificil execução (BEDUSCHI FILHO et al, 2004; FAVARETO, 2006). Dessa forma, as ações resultantes desta nova concepção por parte do governo não surtiram muitos efeitos, para além da importância de redefinição de responsabilidades, onde o desenvolvimento passou a se atrelar as escalas municipais, regionais e territoriais, mais nenhum resultado alterou o quadro de crise e externalidades da esfera agrária brasileira.

A política social de desenvolvimento territorial, por exemplo, não possibilitou a ampliação da esfera democrático-participativa, numa nova

4 Para este assunto, ver: ZANI (2010); MELO (2011); OLIVEIRA et al (2011); LOPES (2012); MELO et al (2015). 
significação do conceito de políticas públicas e de desenvolvimento regional, repactuando assim, a relação entre Estado e sociedade civil, pois a configuração de novos arranjos institucionais na gestão públicafoi realizada verticalmente, sem preparo ou conscientização necessária para a população beneficiada. Em meio a essa dinâmica constatou-se a presença de uma estratégia de desenvolvimento territorial no Brasil de forma tecnocrática e distante das reais necessidades e expectativas dos atores locais do campo brasileiro.

Com os pressupostos acima evidenciados, é possível fazer algumas inferências de que a estratégia de desenvolvimento territorial dos governos de Fernando Henrique Cardoso, Luís Inácio Lula da Silva e Dilma Rousseff, com algum avanço qualitativo na formulação e implementação de políticas públicas, vacilou entre ser uma proposta concreta garantidora para a qualidade de vida das pessoas do campo (CRUZ, 2013).

O processo de desconcentração industrial iniciado nos anos 70 , a Constituição de 1988 (CF/88) e a descentralização administrativa nos anos 90, não se fizeram sentir nos governos do início do século XXI, os incentivos a favor da autonomia de organizações civis e instituições locais sob a forma de câmaras setoriais, conselhos, comitês, agências e consórcios espalhados no país, não ultrapassaram os limites municipais e regionais e não garantiram assim uma independência em relação à União.

A localidade quando passou a ter prevalência, herdou, por sua vez, os vícios anteriormente perceptiveis na esfera federal - clientelismo, patrimonialismo e insulamento burocrático - obstaculizando a possibilidade do desenvolvimento territorial se fundamentar no processo de transformação gradual da estrutura política e social de populações inteiras, de forma a racionalizar o espaço-tempo-natureza com o modo de vida de suas populações, na perspectiva de associar as políticas públicas a uma identidade/comunidade territorial. Esse processo de desenvolvimento não teve como princípio político o alargamento do cânone democrático, que transitaria entre a democracia representativa e a participativa (COELHO, 
NOBRE, 2004), trouxe por sua vez, o aumento da descrença, do inconformismo e do alargamento da desigualdade.

A nova conformação societária imaginada/desenhada pelas politicas públicas territoriais, não levaram em consideração a precariedade das instituições brasileiras e de sua nocividade para realização de ações democráticas. Os governos locais não estavam suficientemente amadurecidos para agirem de forma coordenada e autônoma como previam as últimas e transitórias políticas territoriais: Pronaf, Pronat e PTC (ver quadro 1).

As ações inicialmente impulsionadas com a criação do Pronaf, através do Decreto 1.946, tinha por objetivo, promover o desenvolvimento sustentável da agricultura familiar. Estas posteriormente demonstraram-se residuais e pouco propícias para a alteração necessária em prol do desenvolvimento territorial das áreas rurais brasileiras (já que essa política restringe-se a financiamento da produção agropecuária).

Levando em consideração a eficácia do programa, verifica-se a existência de alguns descompassos, por mais que o desenho institucional fosse inicialmente promissor. Os municípios beneficiados com recursos do Pronaf eram escolhidos tendo por base parametrizado o baixo desempenho no Índice de Desenvolvimento Humano (IDH), o que demonstrava uma intenção para dinamizar o desenvolvimento e equalizar os investimentos federais. Em 2001, o programa passou a dar relevância a projetos de caráter intermunicipal a partir de uma combinação de critérios que envolviam a presença de agricultores familiares e assentados da reforma agrária e, novamente, a ocorrência de baixo IDH.

O Pronaf ainda hoje é vinculado às rubricas orçamentárias e aos fluxos da hierarquia administrativos federais relativos aos programas de combate à pobreza. Com isso, apresenta como externalidade o fato de não ser uma política permanente, não dispondo de articulação com outras politicas estruturais do governo federal. Os primeiros arranjos institucionais em favor da participação da comunidade, favorecendo as demandas dos trabalhadores rurais iniciam-se apenas com a execução do segundo 
programa de desenvolvimento territorial - o Pronaf - verificando-se a presença institucionalizada dos Conselhos Municipais de Desenvolvimento Rural (CMDRS), órgãos colegiados para diálogo e conformação para a execução do programa e que será modelo para a elaboração do PTC. É neste período, com a conjuntura favorável em prol dos movimentos sociais do campo, que se institui a Secretaria de Desenvolvimento Territorial (SDT) inserida no Ministério do Desenvolvimento Agrário (MDA), tendo por finalidade, se incumbir de elaborar estratégias para a política de desenvolvimento rural, focados na dinamização de conjuntos municipais (territórios) considerados deprimidos, tendo no conselho gestor bipartite o principal espaço para a construção de propostas e definição das prioridades dos recursos do Programa.

Posteriormente, em 2008, o governo federal lança o PTC, ampliação do Pronat, que tem como objetivos promover o desenvolvimento econômico e universalizar programas básicos de cidadania por meio de uma estratégia de desenvolvimento territorial sustentável. Todos esses programas - Pronaf, Pronat e PTC - tinham por intuito três pressupostos básicos, que eram respectivamente: 1) conter o conflito no campo entre latifundiários e trabalhadores sem terra; 2) fortalecer a tônica dos assentamentos rurais ao invés da realização e fortalecimento da política de reforma agrária e; 3) desenvolver os territórios rurais a partir da modernização rural, inserindo a categoria de trabalhadores rurais familiares como nomenclatura mitigadora e dependente/cooperativa da cadeira produtiva do agronegócio. (ver figura 1). Dos três programas executados, o PTC apresentava-se como o modelo de maior potencial de sucesso e mais complexo institucionalmente, tanto que tinha por característica particular a participação de diversas pastas ministeriais para o alcance de seus resultados. Suas metas eram transversais e priorizavam: a) o combate à extrema pobreza e a segurança alimentar; b) o fortalecimento de grupos identitários; e c) o desenvolvimento territorial a partir da produção harmônica entre pequenos e grandes produtores rurais. A execução deste programa é uma realização natimorta, seus objetivos ficaram restritos à fase de elaboração e desenho da proposta, 
que, sem dúvida alguma, parece ser até hoje a melhor ação pública pensada/imaginada para a esfera agrária brasileira.

Após a morte prematura do PTC, restou à população rural a permanência de sua situação de penúria, conflito, desigualdade e de distanciamento do protagonismo/desenvolvimento do território como espaço de oportunidades e de ressignificações para suas vidas, levando ao retorno das mazelas provenientes do conflito entre o uso e a posse da terra, entre latifundiários e trabalhadores rurais, na qual os efeitos mitigadores já não mais se fazem presente na agenda política do país.

\section{Figura 1- Objetivos comuns das três politicas brasileiras de desenvolvimento territorial}

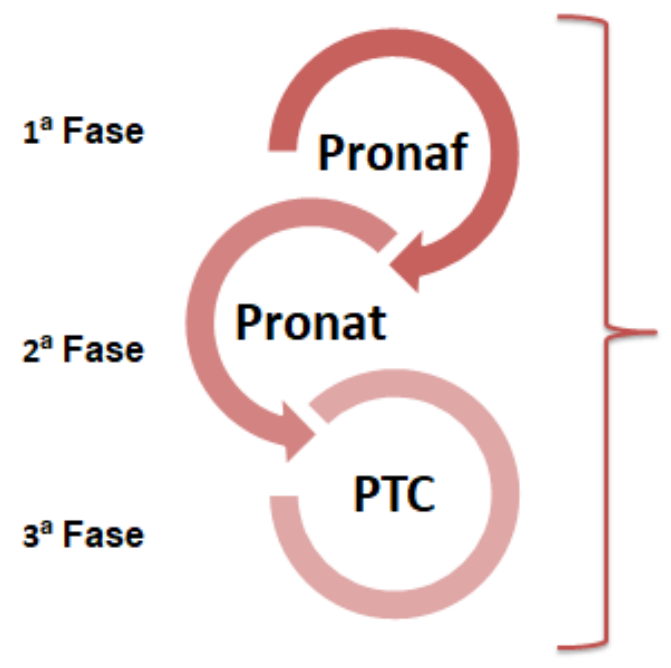

PRINCIPAIS OBJETIVOS COMUNS:

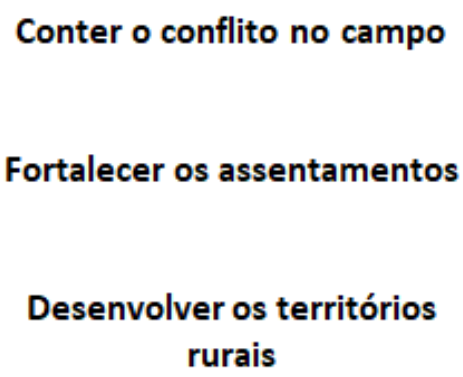

Fonte: Elaboração própria

\section{A semente não germinada: uma importante elaboração política sem a concretude necessária}

O PTC foi criado em 2008 como uma das principais iniciativas do governo federal para a promoção do desenvolvimento territorial e superação da pobreza rural. O PTC, com forte influência do Pronat, teve por diferenciação ser um programa de abrangência nacional, atendendo a 120 territórios, e de escopo desenhado com o objetivo principal de reduzir as desigualdades sociais em áreas rurais. Isto é ressaltado em seu decreto: 
"Promover e acelerar a superação da pobreza e das desigualdades sociais no meio rural, inclusive as de gênero, raça e etnia, por meio de estratégia de desenvolvimento territorial sustentável” (BRASIL, 2008, p. 13).

O novo programa passou a assistir automaticamente a todos os territórios rurais atendidos até então pelo Pronat, tendo por característica atender os territórios economicamente mais fragilizados, enquadrados em certos critérios de elegibilidade, a saber: 1) territórios com baixos Índices de Desenvolvimento Humano (IDH); 2) baixo Índice de Desenvolvimento da Educação Básica (IDEB); 3) maior concentração de agricultores familiares ou assentados da reforma agrária; 4) maior concentração de comunidades quilombolas ou população indígena; e 5) municípios com baixo dinamismo econômico.

As ações do PTC eram vinculadas a três grandes eixos de atuação, respectivamente: (I) Apoio a Atividades Produtivas; (II) Infraestrutura; (III) Cidadania e direito. Estes eixos se desdobravam em sete outros temas, que eram: (a) Organização Sustentável da Produção; (b) Ações Fundiárias; Educação e Cultura; (c) Direitos e Desenvolvimento Social; (d) Saúde, Saneamento e Acesso à Água; (e) Apoio à Gestão Territorial e Infraestrutura.

As ações de desenvolvimento territorial, iniciadas nos governos do PSDB e posteriormente dado prosseguimento nos governos do PT, apresentavam em todas as suas conformações institucionais suas respectivas especificidades, entretanto, foi o PTC que apresentou quatro características peculiares que o diferenciava muito dos demais programas, tendo sido considerado como o mais promissor em um conjunto de ações realizadas pelo MDA. Nele se verifica: i) a abordagem territorial como estratégica; ii) a gestão social como variável em prol da participação; iii) a necessária convergência dos programas sociais com as ações territoriais e iv) a intersetorialidade como um pressuposto a ser perseguido (ZANI, 2010; CAZELLA et al, 2013; ANDRADE, 2015)

O desenho diferenciado de ação fugiu das escalas já conhecidas (municipal, estadual, federal), passando a se utilizar da escala territorial para execução de suas ações; a gestão social tentou ser empregada para 
trazer a população e as demandas locais para próximo das decisões dos gestores públicos; a convergência de programas sociais foi imaginada para facilitar a alocação de recursos em áreas prioritárias, facilitando a administração do programa e a intersetorialidade buscou aproximar o diálogo entre ministérios, esforçando-se em fortalecer a relação com os demais entes federativos.

A gestão do programa de caráter interministerial, composta por um Comitê Nacional formado por 21 ministérios, ficava responsável pela articulação e monitoramento do programa. Além do Comitê Nacional, a gestão do programa também era composta pelo Comitê de Articulação Estadual e pelos Colegiados Territoriais. O Comitê de Articulação Estadual era formado por órgãos federais, estaduais e representações das prefeituras dos territórios, possuindo caráter consultivo e propositivo. Já os colegiados eram constituídos por representantes das três esferas de governo e da sociedade civil.

Conforme destacam Cazella et al. (2013), outro ponto inovador do programa era a respectiva "matriz de ações". Esta importante ferramenta presente no programa tinha por finalidade apresentar matricialmente a cada ano, as respectivas ações prioritárias para cada um dos territórios. Por exemplo, no ano de 2013, foram realizadas ações em cada um dos 120 territórios, totalizando pouco mais de 18,9 bilhões de reais, mobilizando áreas como: 1) Organização sustentável da produção; 2) Educação e cultura; 3) Saúde, saneamento e acesso à água; 4) Direitos e desenvolvimento social; 5) Infraestrutura; 6) Apoio à gestão territorial; e7) Ações fundiárias envolvendo diferentes programas e projetos sociais.

O PTC atuou em grande parte do território nacional, totalizando 120 territórios e de acordo com dados do Censo Demográfico de 2010, o programa atendia 33,3\% dos municípios brasileiros, correspondendo a 1.851 cidades, correspondendo a cobertura de $23,4 \%$ da população brasileira, com destaque para região Norte do país, com cerca de $60 \%$ da população da região. Ainda de acordo com o censo de 2010, o PTC cobriu quase metade da população rural brasileira, correspondendo a 13.691 .619 pessoas; cerca de 
410 mil índios, correspondendo a 49,86\% da população indígena brasileira e cerca de 230 mil pescadores, correspondendo a $56,2 \%$ da população de pescadores do país.

De acordo com dados do então Ministério de Desenvolvimento Social e Combate a Fome, no ano de 2010, 4,66 milhões de famílias residentes nos territórios da cidadania recebiam bolsa família, correspondendo a $37,5 \%$ do total de famílias beneficiárias do país (ANDRADE, 2015). Ainda segundo Andrade (2015), de acordo com dados da Fundação Cultural Palmares, até o ano de 2010, cerca de 390 municípios que pertenciam a territórios da cidadania possuíam pelo menos uma comunidade quilombola certificada, representando $54,5 \%$ do total de municipios que possuíam pelo menos um quilombo no país (ver figura 2).

O PTC apresentou-se como a principal iniciativa do governo federal desde a redemocratização para superação da pobreza rural com enfoque especial para populações tradicionais. Pode se admitir que sem dúvida alguma foi a ação pública mais próxima a trabalhar a multidimensionalidade da pobreza e a defender um desenvolvimento endógeno e cooperativo entre os atores da esfera agrária brasileira. Sua curta duração não possibilita uma avaliação apropriada do método utilizado em relação aos objetivos e metas a serem alcançados, mas demonstra que o caminho para a resolução dos conflitos no campo é diretamente impactada pela ação propositiva do Estado em direção a um projeto de desenvolvimento para toda esta população.

\section{Figura 2- Dados sintéticos dos resultados do Programa Territórios da Cidadania}




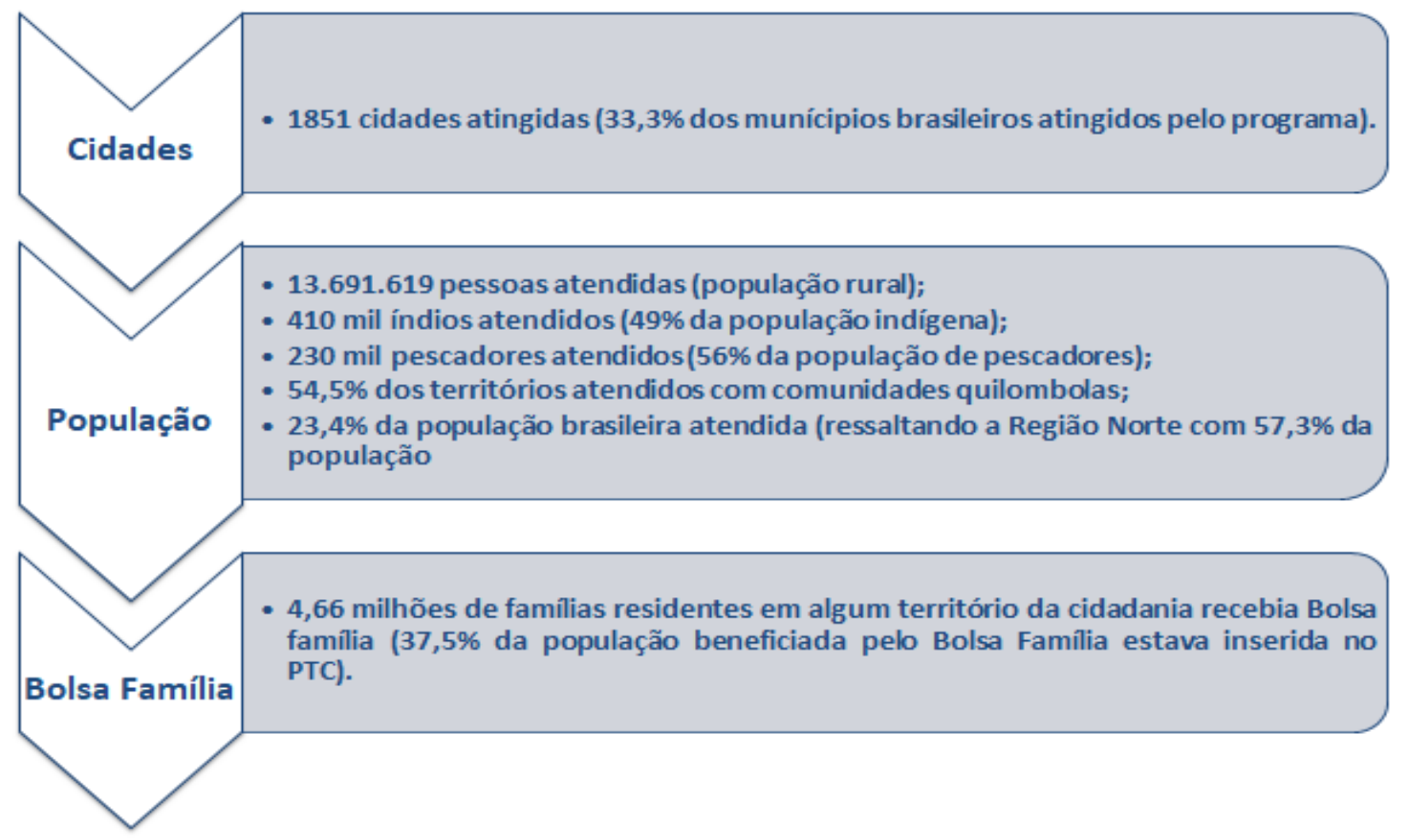

Fonte: Elaboração própria.

O breve período de execução do PTC e o seu abandono nos anos de 2014 revelam que os resultados alcançados foram promissores em direção a uma reordenação do desenvolvimento agrário. A lógica interministerial que era uma inovação deste programa e sua íntima conexão com os programas de segurança alimentar e os movimentos sociais demonstravam que o relativo sucesso em direção ao combate à extrema pobreza estava direcionando-se para uma nova fase de conquistas. É evidente que o programa também apresentava importantes erros de execução e que inevitavelmente seria foco de reavaliações e monitoramento, entretanto, as ações foram prematuramente encerradas, voltou-se a privilegiar apenas o financiamento e o investimento da produção agrícola. A compreensão sobre o desenvolvimento territorial e das políticas a serem executadas retrocederam a concepção realizada no início da década de 1990, o que permite considerar que os conflitos no campo e a extrema pobreza voltarão a ser sentido de forma mais proeminente, tornando a esfera agrária brasileira um permanente espaço de iniquidades, desigualdades e concentração de renda.

\section{Considerações Finais}


Este trabalho buscou ressaltar quatro pontos fundamentais para o alcance das politicas territoriais brasileiras, que acabaram por se materializar na execução do PTC, que eram respectivamente: 1) a importância do conceito de território, evidenciando as interpretações conceituais estabelecidas pela Geografia e demais disciplinas, até a adoção do conceito de multiterritorialidade; 2) os impactos e as influências tidas no Brasil e na América Latina após a acepção do conceito de multiterritorialidade e de empowerment, por parte de importantes agências multilaterais e fortalecidas após a execução de um dos maiores programas de desenvolvimento territoriais realizados pelos países europeus (o programa LEADER); 3) a importância dada às politicas sociais a partir da Constituição Federal 1988 e como estas passaram a conversar com as políticas desenvolvimento territorial no Brasil no final da década de 1990; e 4) os principais objetivos do PTC, que tinha como pressuposto basilar o desenvolvimento para as áreas rurais, a partir de ações e metas que se coadunavam em três pilares: a) o combate à pobreza; b) o fortalecimento da participação social - dando autonomia decisória aos atores locais e; c) a adoção da intersetorialidade 5 na execução do programa.

Tais mudanças afetaram o Brasil, que após tentativas de incorporar um desenho mais efetivo para a abordagem territorial nas politicas de desenvolvimento rural, chegou a elaborar uma politica pública próxima aos marcos institucionais e conceituais que outros países da América Latina e Europa estavam adotando, obtendo avanços e abrindo-se a investimentos externos de importantes agências multilaterais, principalmente após a execução dos programas: Pronat e PTC.

As politicas territoriais executadas, senão apresentaram mais sucesso e resultados, explicam-se por terem sido pouco combativas com algumas distorções presentemente constatadas na politica agrária brasileira, tais como: (i) a dificuldade de descentralização da execução da política e seu

\footnotetext{
5 Por intersetorialidade, o MDA entende que seja a atuação de uma gestão de forma integrada entre ministérios e as decisões a serem executadas, possibilitando, por sua vez, a inserção da sociedade civil nas decisões, o que fortalece as ações de diferentes setores envolvidos na política, levando assim ao atendimento das demandas internas de cada localidade.
} 
possivel desvio de finalidade; (ii) a concentração de crédito e o favorecimento "seletivo" na política de subsídios para favorecimento de interesses privados de alguns atores políticos municipais e; (iii) a hipertrofia da presença estatal, atuando em interesses e áreas que antes deveriam ser estimuladas do que meramente financiadas - favorecendo posturas paternalistas dos atores políticos com a sociedade.

Os erros pelos quais passaram as politicas territoriais brasileiras se devem muito fortemente à cultura politica brasileira - paternalista; patrimonialista e clientelista (NUNES, 2003)-, mas também da adoção automática de pressupostos, modelos e teorias de outros países, não havendo a devida atenção para se evitar as distorções/desvios das novas concepções institucionais assimiladas. Uma possivel correção de rumo para futuras ações é a de priorizarmos o caráter multissetorial, separando as ações sociais das setoriais e produtivas, visando simplificar o desenho dos programas territoriais. Isto abrangeria, por sua vez, áreas mais próximas em termos de segmentos econômicos, identidade cultural e práticas sociais possiveis para realizar as necessárias ações em prol do desenvolvimento das localidades atendidas.

Quanto aos avanços obtidos sobre a interpretação do conceito de território, verifica-se: (i) a busca pela compreensão do espaço, para além da dicotomia campo-cidade e; (ii) o abandono de um horizonte estritamente setorial, o que ajuda a ampliar a compreensão do espaço rural para além do agrícola. Essas ações fortalecem de forma significativa o conceito de multifuncionalidade do território na gestão publica, favorecendo uma nova fase da política de desenvolvimento territorial brasileira, que não deve ser negligenciada no futuro.

Logicamente que não é a intenção deste trabalho reduzir os avanços e retrocessos da política de desenvolvimento territorial do país às gestões do final da década de 1990 e as políticas recém-executadas. O desenvolvimento aqui preconizado não está descolado da compreensão de que todo quadro de alteração de realidade socioeconômica é inevitavelmente proveniente de um acúmulo histórico de ação política, de reivindicação de direitos por parte das 
organizações sociais e da capacidade técnica de funcionários, técnicos, líderes territoriais e líderes politicos em responder e ressignificar expectativas, demandas, interesses e conflitos. Ou seja, é um processo que se inicia antes da construção da atual institucionalidade relacionada ao PTC e que não apresentará um fim idealizado ou tecnicamente/intelectualmente construído como resposta aos problemas da questão agrária brasileira. O que aqui está sendo ressaltado não é a possibilidade de soluções mágicas, mas a necessidade e urgência de novamente debatermos e colocarmos essa importante pauta na agenda politica brasileira.

Quando analisados alguns importantes pressupostos conceituais no caso aqui tratado, consideramos que o avanço na direção dos "Territórios da Cidadania" foi promissor, embora seus frutos não tenham se feito sentir de maneira muito vigorosa ${ }^{6}$. O programa possibilitou estabelecer a perspectiva da multifuncionalidade do território, a participação como variável estratégica e o combate à pobreza, pressupostos que não podem ser perdidos em futuras reflexões sobre o desenvolvimento territorial. Os novos desafios estão em tentar manter rígidos alguns avanços conquistados e organizar setorialmente o governo em direção a ações de desenvolvimento do território, ainda mais após o desmantelo institucional e político oqual o país ainda atravessa.

\section{Referências}

ABRAMOVAY, R. Representatividade e Inovação. Seminário Nacional de Desenvolvimento Rural Sustentável. Texto para discussão. Brasilia, 25 de agosto de 2005.

ANDRADE, P. G. Critérios de elegibilidade para um municipio pertencer ao Programa Territórios da Cidadania. Dissertação de mestrado do curso de Estudos Populacionais e Pesquisas Sociais, da Escola Nacional de Ciências Estatísticas, Rio de Janeiro, 2015.

BEDUSCHI FILHO, L. C.; ABRAMOVAY, R. Desafio para o desenvolvimento das regiões rurais. Nova Economia. Belo Horizonte, v. 14, n. 3, p. 35-70. set-dez. 2004.

6 Ver: ZANI, (2010); LOPES et al (2011). 
BRASIL. Decreto não numerado de 24 de novembro de 2011. Altera o Decreto de 25 de fevereiro de 2008, que institui o Programa Territórios da Cidadania. 2008.

CAZELlA, A. A; ZIMMERMANN, S. A; LEITE, S. P. A gestão do Programa Territórios da Cidadania no Brasil: análise das ações e políticas implementadas. Perspectivas Rurales. Nueva época, Ano 11, n. 22, 2013.

COELHO, V. S. P. \& NOBRE, M. (Orgs.). Participação e deliberação: teoria democrática e experiências institucionais no Brasil contemporâneo. São Paulo: Ed. 34, 2004.

CORREAA, R. L. Territorialidade e corporação: um exemplo. In: SANTOS, M.; SOUZA, M. A.; SILVEIRA, M. L. [Orgs.], Territórios Globalização e Fragmentação, ed. Hucitec, São Paulo. 1994.

CRUZ, D. Um Estudo das politicas públicas de Desenvolvimento Territorial na Bahia: Democracia e Participação. Encontro de Administração Política, 2013.

FAVARETO, A. Paradigmas do desenvolvimento rural em questão - do agrário ao territorial. 2006. 220 f. Tese (Doutorado em Ciência Ambiental). Universidade de São Paulo, São Paulo, 2006.

A abordagem territorial do desenvolvimento rural - mudança instituição ou "inovação por adição". Estudos Avançados 24(68), 2010.

HAESBAERT, R. Território e Multiterritorialidade: um debate. In: GEOgraphia - Ano $I X-N o 17-2007$.

HESPANHOL. N. Modernização da agricultura e desenvolvimento territorial. In: Encontro Nacional de Grupos de Pesquisa - ENGRUP. 4; AGRÁRIA/DG/FFLCH/USP.2008, São Paulo. Anais...São Paulo: 2008. p. 370-392.

LOPES, J. F. R. Território e participação política: o colegiado territorial Norte fluminense. Dissertação apresentada ao programa de mestrado da Escola Brasileira de Administração Pública e de Empresas da Fundação Getulio Vargas, FGV, 2012.

LOPES, J.; MELO, W.; FRAGA, M. Nem Desenvolvimento, Nem Territorial: Sobre Falácias no Discurso das Políticas Territoriais. II Seminário Nacional Espaço e Economia: Políticas Territoriais, Intervenção do Estado e Práticas Sociais na Reestruturação do Espaço. Rio de Janeiro: UERJ, 2011. Disponivel em: <http://www.nupee.com.br/>

MELO, W. Quando o passado se faz presente: Os desafios da gestão social no Programa Nacional de Agricultura Familiar. 1. ed. Saarbrücken: Novas Edições Acadêmicas, 2014. v. 1. 160p. 
MELO, W; ANDRADE, P.G; AZEM, P. A participação como variável: a importância dos conselhos na atual politica de desenvolvimento territorial no Brasil. XII Congresso de Ciências Sociais e Humanas em Lingua Portuguesa, Portugal/Lisboa, 2015.

MINISTÉRIO DO DESENVOLVIMENTO AGRÁRIO. SECRETARIA DE DESENVOLVIMENTO TERRITORIAL. Territórios da Cidadania: integração de politicas públicas para reduzir as desigualdades. Brasília: MDA, 2009.

NUNES, E. A gramática politica do Brasil. Rio de Janeiro: Zahar, 2003.

OLIVEIRA, J. R.; ALlEBRANT, S. L. ; SAUSEN, J. O.; TENÓRIO, F. G. A Gestão Social no Contexto do Programa Territórios da Cidadania: os casos dos Municípios de Braga, Campo Novo e Coronel Bicaco - RS. Administração Pública e Gestão Social, v. 3, p. 43-65, 2011.

ORTEGA, A. C.; MENDONÇA, N. C. Estratégias de desenvolvimento rural no Brasil: continuidades e rupturas. In: ALMEIDA FILHO, N. (Org.). Desenvolvimento territorial: Segurança Alimentar e economia solidária. Campinas: Alinea, 2008.

RAFFESTIN, C. Por uma Geografia do Poder. São Paulo: Ática. 1993.

ROVER, Ó. J.; HENRIQUES, M. A. A gestão democrática em debate: O programa LEADER e a sua relação com a sociedade civil local. Revista Critica de Ciências Sociais, n. 75, p.117-137, out 2006.

SACK, R. D. O Significado da Territorialidade. In: DIAS, L. C. \& FERRARI, M. [Orgs]. Territorialidades Humanas e Redes Sociais. Insular, Florianópolis. 2011.

SEPÚlVEDA, S.; GUIMARÃES, M. D. Gestión del desarrollo Sostenible en Territórios Rurales em Brasil. San José, C.R.: IICA, 2008.

SOUZA, M. J. L. O Território: Sobre o Espaço e Poder, Autonomia e Desenvolvimento In: CASTRO, I. E. de; GOMES, P. C. da C.; CORREA, R. L. [orgs.] Geografia: Conceitos e Temas. 2007.

ZANI, F. B. Gestão social do desenvolvimento: a exclusão dos representantes dos empresários? O caso do Programa Territórios da Cidadania Norte-RJ. Dissertação apresentada ao programa de mestrado da Escola Brasileira de Administração Pública e de Empresas da Fundação Getulio Vargas, FGV, 2010. 